\title{
openheart Factors influencing long-term heart failure mortality in patients with obstructive hypertrophic cardiomyopathy in Western Sweden: probable dose-related protection from beta-blocker therapy
}

\author{
Davood Javidgonbadi, ${ }^{1}$ Bert Andersson, ${ }^{\oplus 1}$ Nils-Johan Abdon, ${ }^{2}$ \\ Maria Schaufelberger, ${ }^{1}$ Ingegerd Östman-Smith ${ }^{\oplus}$
}

\begin{abstract}
- Additional material is published online only. To view please visit the journal online (http://dx.doi.org/10.1136/ openhrt-2018-000963)

To cite: Javidgonbadi $\mathrm{D}$, Andersson B, Abdon N-J, et al Factors influencing long-term heart failure mortality in patients with obstructive hypertrophic cardiomyopathy in Western Sweden: probable dose-related protection from beta-blocker therapy. Open Heart 2019;6:e000963. doi:10.1136/ openhrt-2018-000963
\end{abstract}

Received 11 November 2018 Revised 3 May 2019 Accepted 30 May 2019

D Check for updates

(c) Author(s) (or their employer(s)) 2019. Re-use permitted under CC BY-NC. No commercial re-use. See rights and permissions. Published by BMJ.

For numbered affiliations see end of article.

Correspondence to Ingegerd Östman-Smith; ingegerd.ostman-smith@pediat. gu.se

\section{ABSTRACT}

Objective In order to avoid effects of referral bias, we assessed risk factors for disease-related mortality in a geographical cohort of patients with hypertrophic obstructive cardiomyopathy (HOCM), and any therapy effect on survival.

Methods Diagnostic databases in 10 hospitals in the West Götaland Region yielded 251 adult patients with HOCM (128 male, 123 female). Case notes were reviewed for clinical data and ECG and ultrasound findings. Betablockers were used in $71.3 \%$ of patients from diagnosis (median metoprolol-equivalent dose of $125 \mathrm{mg} /$ day), and at latest follow-up in 86.1\%; 121 patients had medical therapy alone, 88 short atrioventricular delay pacing and 42 surgical myectomy. Mean follow-up was $14.4 \pm 8.9$ $($ mean $\pm S D)$ years. Primary endpoint was disease-related death, and secondary endpoint heart failure deaths.

Results There were 65 primary endpoint events. Independent risk factors for disease-related death on multivariate Cox hazard regression were: female sex $(p=0.005)$, age at diagnosis $(p<0.001)$, outflow gradient $\geq 50 \mathrm{~mm} \mathrm{Hg}$ at diagnosis $(p=0.036)$ and at follow-up $(p=0.001)$. Heart failure caused $62 \%$ of deaths, and sudden cardiac death $17 \%$. Late independent predictors of heart failure death were: female $\operatorname{sex}(p=0.003)$, outflow gradient $\geq 50 \mathrm{~mm} \mathrm{Hg}$ at latest follow-up ( $p=0.032$ ), verapamil/diltiazem therapy $(\mathrm{p}=0.012)$ and coexisting hypertension ( $p=0.031)$, but not other comorbidities. Neither myectomy nor pacing modified survival, but early and maintained beta-blocker therapy was associated with dose-dependent reduction in disease-related mortality in the multivariate model ( $p=0.028)$, and final dose was also associated with reduced heart failure mortality $(p=0.008)$. Kaplan-Meier survival curves analysed in initial dose bands of $0-74,75-149$ and $\geq 150 \mathrm{mg}$ metoprolol/day showed 10-year freedom from disease-related deaths of $83.1 \%, 90.7 \%$ and $97.0 \%$, respectively $\left(\mathrm{p}_{\text {trend }}=0.00008\right)$. Even after successful relief of outflow obstruction by intervention, there was survival benefit of metoprolol doses $\geq 100 \mathrm{mg} /$ day $(p=0.01)$.

Conclusions In population-based HOCM cohorts heart failure is a dominant cause of death and on multivariate

\section{Key questions}

What is already known about this subject?

- Much research on patients with hypertrophic cardiomyopathy (HCM) has come from tertiary centre populations with possible referral bias for patients with a malignant family history. In those populations sudden cardiac death (SCD) has been an important proportion of disease-related mortality. Major risk factors for SCD include extreme cardiac hypertrophy, cardiac syncope and a malignant family history. Left ventricular outflow tract obstruction is considered a minor risk factor.

What does this study add?

- This study on a complete geographical cohort of patients with obstructive HCM, and long and 100\% complete follow-up, shows that heart failure caused a majority $(62 \%)$ of disease-related deaths, and that SCD only constituted $17 \%$ of deaths. Furthermore, this study is the first to demonstrate on multivariate analysis the independent risk factors specifically for heart failure death: female sex, verapamil/diltiazem therapy, coexisting systemic hypertension and outflow gradient $\geq 50 \mathrm{~mm} \mathrm{Hg}$. Thus, risk factors for heart failure death are different from those for SCD. This study also suggests that pharmacotherapy with beta-blockers in doses similar to target doses for dilated cardiomyopathy is associated with reduced risk of heart failure death in a dose-dependent fashion.

analysis beta-blocker therapy was associated with a dosedependent cardioprotective effect on total, disease-related as well as heart failure-related mortality.

\section{INTRODUCTION}

Hypertrophic cardiomyopathy (HCM) is often associated with a dynamic muscular 


\section{Key questions}

How might this impact on clinical practice?

- American Heart Association guidelines suggest that symptom-free left ventricular outflow tract obstruction need not be treated, but our results indicate that in obstructive HCM there is survival benefit from pharmacotherapy with beta-blockers, even in those patients where interventional treatment has reduced gradient to $<30 \mathrm{~mm}$ $\mathrm{Hg}$. Furthermore, our results suggest that other risk factors like systemic hypertension need optimal control, and that perhaps calcium channel blockers should be avoided in this patient group.

outflow tract obstruction, and tertiary centres report that outflow tract obstruction is a risk factor for both more rapid symptomatic deterioration and death. ${ }^{1}$ Nevertheless, the American Heart Association (AHA) guidelines for treatment of HCM suggest that left ventricular outflow tract obstruction (LVOTO) without symptoms does not necessarily need treatment. ${ }^{2}$ Whereas LVOTO is not considered a major risk factor in the AHA 2011 guidelines, ${ }^{2}$ it is included in the latest European Society of Cardiology algorithm for assessing risk of sudden cardiac death (SCD). ${ }^{3}$ Most studies on risk factors have emanated from specialised tertiary centres subject to possible referral bias. Therefore, we studied the longterm outcome of patients with hypertrophic obstructive cardiomyopathy (HOCM) in an unselected complete geographical cohort in order to assess risk factors for adverse outcome. No long-term prospective randomised trials of the effect of currently used therapy on survival have been performed so far, thus we included possible effect on survival of drug therapy, myectomy and pacing in the analysis.

\section{MATERIALS AND METHODS Patient population}

Adult cardiac care for the 1.6 million inhabitants of West Götaland Region is provided by 10 hospitals (listed in the Acknowledgements section). We searched all hospital diagnostic databases for adult inpatients and outpatients attending hospital from January 2002 to December 2013 with diagnostic codes relating to a diagnosis of HCM, and reviewed the case notes on site to identify those with HCM and outflow tract obstruction (HOCM). Diagnosis of HCM was based on standard clinical criteria as defined previously. ${ }^{4}$ Patients were categorised as HOCM if they had a verified LVOT pressure gradient of $\geq 30 \mathrm{~mm} \mathrm{Hg}$ at rest. ${ }^{3}$ During the study period, 1142 patients had a verified diagnosis of primary $\mathrm{HCM}$, and from that group 251 patients (128 male, 123 female) fulfilled the HOCM criteria.

\section{Therapy modalities employed}

Patients were initially treated medically, and 121 patients remained on medical therapy only, but 130 required interventions, 88 with short atrioventricular delay pacing and 42 with myectomy (flow chart in online supplementary figure S1). Detailed comparisons of haemodynamic and symptomatic outcomes, and of survival, between myectomy and pacing in this cohort have been published and showed equivalent efficacy. ${ }^{5}$ Consequently, in this study we examined the risk factors for disease-related death in the total HOCM group. Type and dose of beta-blocker and calcium-blocker therapy were recorded. For statistical comparison, all beta-blocker doses were converted to equivalent doses of metoprolol (the beta-blocker most commonly employed: $48.6 \%$ metoprolol, $22.7 \%$ bisoprolol, $7.5 \%$ propranolol and $6.7 \%$ atenolol). The conversion used was metoprolol $100 \mathrm{mg}=$ propranolol 80 $\mathrm{mg}^{6}=$ bisoprolol $5 \mathrm{mg}=$ atenolol $50 \mathrm{mg}$.

\section{Clinical measures collected}

Clinical features (including proposed risk factors and comorbidities), ECG and echocardiographic measurements, implantable cardioverter-defibrillator (ICD) therapies and type of medical therapy and dose used were documented at diagnosis, and at latest follow-up visit.

\section{Cause of death}

Vital status was censored on 28 February 2015. The Swedish unique personal identification number allowed us to establish causes of death by death certificates from the National Board of Health and Welfare, in addition to case note review. No patient was lost to follow-up. The primary endpoint was a composite of total cardiac mortality, heart transplantation and fatal embolic stroke of presumed cardiac origin together referred to as 'disease-related death'.

\section{Statistics}

Analysis was carried out by SPSS statistical software, V.22.0 (IBM). The majority of the variables studied did not show a normal distribution, and accordingly those data are presented by median (IQR). Statistical comparisons of paired continuous variables were made by Wilcoxon signed-rank test, and for paired binary data with McNemar test. Survival was analysed by Kaplan-Meier curves and the log-rank test, and comparative analysis of risk factors for the endpoint was carried out by univariate and multivariate Cox proportional hazards method. Variables were selected for multivariate analysis if univariate $p$ values were $\leq 0.20$. The number of variables was restricted to six at a time in our multivariate models in order to have adequate statistical power, and were analysed with backward selection. All tests were two sided, and $\mathrm{p}$ values $<0.05$ were considered statistically significant; variables with $\mathrm{p}<0.10$ on multivariate analysis were kept in multivariate models. Correlations were analysed with Pearson's correlation coefficient for continuous variables and Spearman's rho for categorical data. For intergroup comparisons in online supplementary tables, MannWhitney $\mathrm{U}$ test was used for continuous variables, and two-tailed Fisher's exact test and $\chi^{2}$ test for categorical variables as appropriate. 
Table 1 Characterisation of total cohort at diagnosis and at latest follow-up $(n=251)$, shown as median $(I Q R)$ when not otherwise specified

\begin{tabular}{|c|c|c|c|}
\hline & $\begin{array}{l}\text { At } \\
\text { diagnosis }\end{array}$ & $\begin{array}{l}\text { At latest } \\
\text { follow-up }\end{array}$ & $P$ value \\
\hline Total follow-up (years) & & $13.2(12.4)$ & \\
\hline Age & $56(27)$ & $70(23)$ & \\
\hline Age, male $(n=128)$ & $51(24)$ & $64(21)$ & \\
\hline Age, female $(n=123)$ & $62(20)$ & $75(18)$ & \\
\hline Body mass index & $26(6)$ & $27(7)$ & 0.001 \\
\hline NYHA class (mean \pm SD) & $2.2(0.73)$ & $1.8(0.73)$ & $<0.001$ \\
\hline NYHA class $\geq 11$ I (\%) & 40.4 & 15.8 & $<0.001$ \\
\hline Family history of SCD (\%) & 15.1 & & \\
\hline History of syncope (\%) & 25.4 & & \\
\hline \multicolumn{4}{|c|}{ Transthoracic echocardiogram and ECG measurement: } \\
\hline Septum (mm) & $19(6)$ & $19(5)$ & 0.56 \\
\hline LVPW (mm) & $13(4)$ & $12(5)$ & 0.48 \\
\hline Wall thickness $\geq 30 \mathrm{~mm}(\%)$ & 3.4 & 0.8 & 0.45 \\
\hline LVEDD (mm) & $43(9)$ & $43(7)$ & 0.50 \\
\hline Ejection fraction (\%) & $69(15)$ & $63(10)$ & $<0.001$ \\
\hline LVOT gradient rest $(\mathrm{mm} \mathrm{Hg})$ & $65(57)$ & $16(36)$ & $<0.001$ \\
\hline Left atrium diameter (mm) & $41(15)$ & $48(11)$ & $<0.001$ \\
\hline Sokolow-Lyon index (mm) & $3.3(1.8)$ & $3.1(2.0)$ & 0.62 \\
\hline QTc (ms) & $436(45)$ & $449(49)$ & $<0.001$ \\
\hline Atrial fibrillation (\%) & 4.0 & 30.6 & $<0.001$ \\
\hline \multicolumn{4}{|c|}{ Other comorbidity (proportion in \%): } \\
\hline Systemic hypertension & 13.5 & 37.5 & $<0.001$ \\
\hline Diabetes mellitus & 5.6 & 13.5 & $<0.001$ \\
\hline Coronary artery disease & 3.6 & 13.1 & $<0.001$ \\
\hline Chronic kidney disease & 1.2 & 4.0 & 0.016 \\
\hline $\begin{array}{l}\text { Chronic obstructive } \\
\text { pulmonary disease }\end{array}$ & 6.8 & 8.8 & 0.063 \\
\hline
\end{tabular}

Interindividual paired values are compared with Wilcoxon signed-rank test, normally distributed values with paired t-test and binary data with McNemar test, with proportion positive indicated in per cent. Bold text high-light statistically significant findings.

LVEDD, left ventricle end-diastolic diameter; LVOT, left ventricular outflow tract; LVPW, left ventricle posterior wall; NYHA, New York Heart Association; SCD, sudden cardiac death.

\section{RESULTS}

\section{Characterisation of the cohort}

Mean follow-up was $14.4 \pm 8.8$ years $($ mean \pm SD) and median follow-up 13.2 (IQR=12.4) years. Findings at the time of diagnosis and at latest follow-up are shown in table 1 . The sex distribution was even, but females were generally older. Initial medical therapy consisted of betablocker in $69.7 \%$, verapamil/diltiazem in $10.8 \%$ and in $1.6 \%$ beta-blocker and calcium-blocker were combined; $17.9 \%$ of patients did not receive any initial pharmacotherapy. During follow-up there was improvement in New York Heart Association (NYHA) class with therapy, and reduction in resting LVOT gradient at rest to a median of $16 \mathrm{~mm} \mathrm{Hg}$. However, 21\% had resting gradients remaining $\geq 50 \mathrm{~mm} \mathrm{Hg}$, and $33 \% \geq 30 \mathrm{~mm} \mathrm{Hg}$ at latest assessment. Atrial size and incidence of atrial fibrillation had increased at latest follow-up.

\section{Primary endpoint}

There were 65 primary endpoint events (53 cardiac deaths, 4 heart transplants, 8 embolic deaths) during follow-up consisting of a total of 3614 patient-years. Only 11 deaths $(17 \%)$ were attributed to SCD, with an annual rate of $0.37 \%$ during the first 10 years of follow-up. The majority of deaths were due to heart failure $(62 \%)$, with myocardial infarct $(8 \%)$ and embolic strokes $(12 \%)$ being less common. There were 25 non-cardiac deaths in the cohort.

\section{ICD implantations}

Sixteen patients $(6.4 \%)$ had received ICD implantation (4 secondary, 12 primary prevention). There was one appropriate discharge in 149 patient-years, that is an appropriate annual discharge rate of $0.67 \%$.

\section{Medical therapy employed}

Beta-blocker use increased from $71.3 \%$ at diagnosis to $86.1 \%$ at latest follow-up, with no significant differences between intervention and non-intervention groups (online supplementary table S1). The beta-blocker dose prescribed initially had no significant correlations to NYHA class, chest pain, syncope, outflow gradient or severity of cardiac hypertrophy (correlation coefficients between -0.053 and 0.144 for all). Hence, patients with the most advanced disease did not receive lower doses. The median initial dose prescribed was $125 \mathrm{mg}$ metoprolol/day, and at latest follow-up was $150 \mathrm{mg} /$ day for patients given beta-blockers. Verapamil/diltiazem therapy was given in median doses of $240(\mathrm{IQR}=80) \mathrm{mg} /$ day, and altered only from $12.4 \%$ of patients to $12.7 \%$ at latest follow-up. For other medication, see online supplementary table S1.

\section{Cox hazard analysis of risk factors}

Risk factors at presentation for subsequent disease-related death Among risk factors significantly associated with outcomes on univariate analysis were age at diagnosis, female sex, coronary artery disease and a resting LVOT gradient $\geq 50 \mathrm{~mm} \mathrm{Hg}$. In the multivariate analysis of the whole group, those risk factors except coronary artery disease remained as significant independent risk factors. Comorbidities and accepted risk factors for SCD were not significant risk factors for total disease-related deaths (table 2).

Risk factors that were significantly associated with disease-related mortality were also significantly associated with all-cause mortality (online supplementary table S2).

For heart failure deaths female sex and age were independent risk factors on multivariate analysis (table 2; univariate risk factors, see online supplementary table S3). 
Open Heart

Table 2 Risk factors/protective factors at diagnosis for disease-related and heart failure death on Cox hazard regression

\begin{tabular}{|c|c|c|c|c|c|}
\hline Variable & B & SE & $\operatorname{Exp}(B)$ & 95\% CI Exp(B) & $P$ value \\
\hline \multicolumn{6}{|c|}{ Univariate Cox hazard analysis disease-related death } \\
\hline Female sex & 0.756 & 0.258 & 2.136 & 1.288 to 3.542 & 0.003 \\
\hline Age at diagnosis & 0.045 & 0.008 & 1.046 & 1.028 to 1.063 & $<0.001$ \\
\hline NYHA class $\geq \| l l$ vs $\leq \| l$ & 0.198 & 0.251 & 1.218 & 0.745 to 1.994 & 0.432 \\
\hline Body mass index & -0.047 & 0.032 & 0.954 & 0.896 to 1.016 & 0.143 \\
\hline Systemic hypertension, Yes versus No & 0.554 & 0.366 & 1.740 & 0.850 to 3.565 & 0.130 \\
\hline Diabetes mellitus, Yes versus No & 0.677 & 0.469 & 1.968 & 0.785 to 4.938 & 0.149 \\
\hline Coronary artery disease, Yes versus № & 1.430 & 0.530 & 4.178 & 1.479 to 11.807 & 0.007 \\
\hline Atrial fibrillation, Yes versus No & 0.101 & 1.013 & 1.107 & 0.152 to 8.059 & 0.920 \\
\hline Chronic kidney disease & 0.624 & 0.738 & 1.866 & 0.439 to 7.926 & 0.398 \\
\hline Chronic obstructive pulmonary disease & 0.419 & 0.430 & 1.521 & 0.654 to 3.534 & 0.330 \\
\hline Family history of SCD, Yes versus No & 0.596 & 0.415 & 1.814 & 0.804 to 4.095 & 0.152 \\
\hline History of syncope, Yes versus No & 0.222 & 0.298 & 1.248 & 0.697 to 2.237 & 0.456 \\
\hline History of chest pain, Yes versus No & 0.124 & 0.253 & 1.131 & 0.687 to 1.859 & 0.624 \\
\hline Septum (mm) & -0.023 & 0.029 & 0.977 & 0.924 to 1.033 & 0.417 \\
\hline Septum:cavity ratio & -0.813 & 0.997 & 0.44 & 0.063 to 3.131 & 0.415 \\
\hline Left ventricle wall:cavity ratio & -0.078 & 1.484 & 0.925 & 0.050 to 16.96 & 0.958 \\
\hline Max wall thickness (mm) & -0.022 & 0.028 & 0.978 & 0.925 to 1.035 & 0.445 \\
\hline Max wall thickness $\geq 30$ vs $<30(\mathrm{~mm})$ & 0.222 & 0.720 & 1.248 & 0.304 to 5.120 & 0.758 \\
\hline Left ventricle posterior wall (mm) & 0.029 & 0.047 & 1.029 & 0.939 to 1.128 & 0.540 \\
\hline Initial LVEDD & 0.008 & 0.017 & 1.008 & 0.974 to 1.042 & 0.660 \\
\hline Initial ejection fraction (\%) & -0.819 & 1.137 & 0.441 & 0.047 to 4.095 & 0.471 \\
\hline Left atrium diameter $(\mathrm{mm})$ & 0.023 & 0.014 & 1.023 & 0.995 to 1.053 & 0.112 \\
\hline LVOT gradient (mm Hg) & 0.002 & 0.003 & 1.002 & 0.996 to 1.008 & 0.511 \\
\hline LVOT gradient at rest $\geq 30 \mathrm{vs}<30(\mathrm{~mm} \mathrm{Hg})$ & 0.632 & 0.361 & 1.880 & 0.927 to 3.814 & 0.080 \\
\hline LVOT gradient at rest $\geq 50 \mathrm{vs}<50(\mathrm{~mm} \mathrm{Hg})$ & 0.587 & 0.281 & 1.804 & 1.031 to 3.133 & 0.038 \\
\hline Beta-blocker, Yes versus No & -0.735 & 0.256 & 0.479 & 0.298 to 0.812 & 0.004 \\
\hline Beta-blocker dose (mg/day) & -0.006 & 0.002 & 0.994 & 0.991 to 0.997 & 0.001 \\
\hline Beta-blocker $\geq 100$ vs $<100$ (mg) & -1.121 & 0.291 & 0.330 & 0.191 to 0.581 & $<0.001$ \\
\hline Verapamil/diltiazem use, Yes versus № & 0.891 & 0.320 & 2.441 & 1.314 to 4.553 & 0.005 \\
\hline Verapamil/diltiazem daily dose (mg/day) & 0.003 & 0.001 & 1.003 & 1.001 to 1.006 & 0.014 \\
\hline Statin treatment, Yes versus No & -0.856 & 0.441 & 0.425 & 0.179 to 1.008 & 0.052 \\
\hline \multicolumn{6}{|c|}{ Multivariate Cox hazard analysis, disease-related death (93\% complete data) } \\
\hline Female sex & 0.823 & 0.292 & 2.278 & 1.286 to 4.036 & 0.005 \\
\hline Age & 0.039 & 0.009 & 1.039 & 1.021 to 1.058 & $<0.001$ \\
\hline LVOT gradient at rest $\geq 50 \mathrm{vs}<50(\mathrm{~mm} \mathrm{Hg})$ & 0.631 & 0.301 & 1.879 & 1.042 to 3.388 & 0.036 \\
\hline Beta-blocker dose (mg/day) & -0.004 & 0.002 & 0.996 & 0.992 to 1.000 & 0.028 \\
\hline \multicolumn{6}{|c|}{ Multivariate Cox hazard analysis, heart failure death (93\% complete data) } \\
\hline Female sex & 0.763 & 0.387 & 2.145 & 1.005 to 4.581 & 0.049 \\
\hline Age & 0.060 & 0.014 & 1.062 & 1.034 to 1.091 & $<0.001$ \\
\hline Beta-blocker dose (mg/day) & -0.005 & 0.003 & 0.995 & 0.990 to 1.001 & 0.080 \\
\hline
\end{tabular}

Significant negative values of $B$ suggest reduction in risk. Bold text high-light statistically significant findings.

LVEDD, left ventricle end-diastolic diameter; LVOT, left ventricular outflow tract; NYHA, New York Heart Association; SCD, sudden cardiac death. 


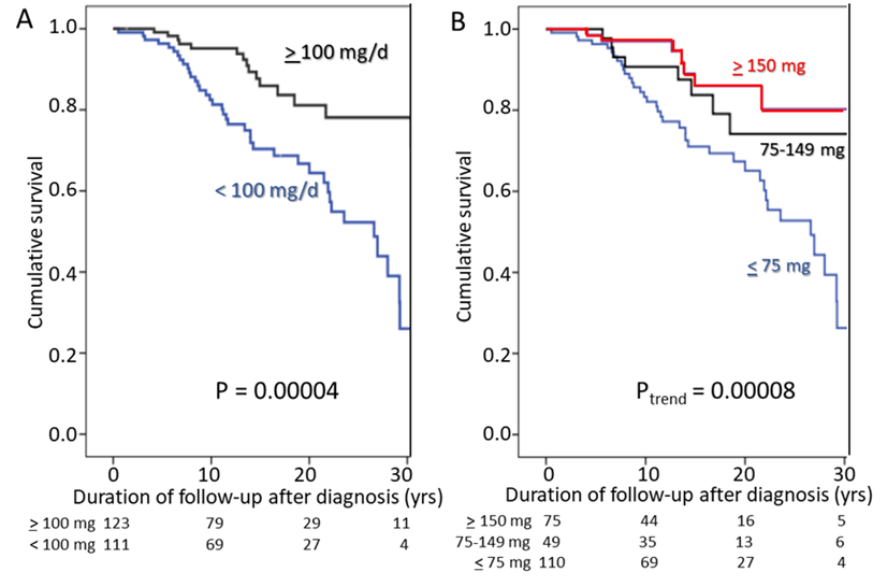

Figure 1 (A) Kaplan-Meier survival curve illustrating freedom from disease-related death in patients with initial beta-blocker dose 0-99 mg/kg, that is, less than the total cohort median dose of $100 \mathrm{mg}$ metoprolol equivalents/day (blue curve), or equal to or greater than 100 mg/day (black curve), who on log-rank testing have significantly superior survival $(p=0.00004)$. (B) Kaplan-Meier survival curves showing freedom from disease-related death in patients receiving 0-74 mg/day (blue curve), 75-149 mg/day (black curve) or $\geq 150 \mathrm{mg} /$ day (red curve) in metoprolol equivalents, with increasing daily dose showing significant trend of improvement $(p=0.00008)$. The numbers below the curves indicate the number of patients remaining in the survival curves.

\section{Influence of therapy choice on survival}

Neither pacing nor myectomy reduced disease-related deaths significantly, whereas use of beta-blocker therapy started at diagnosis was associated with reduced risk on univariate Cox hazard analysis $(\mathrm{p}=0.004)$. The association with outcome appeared to be dose dependent with reduced risk with increased daily dose $(p=0.001)$ and dose dependency remained significant in the multivariate analysis $(p=0.028$; table 2$)$, also for heart failure deaths specifically (table 2; online supplementary table S3). The HR between early beta-blocker use and non-use was 0.49 (95\% CI 0.30 to 0.81 ), $\mathrm{p}=0.006$. Freedom from disease-related deaths for patients given $\geq 100 \mathrm{mg}$ /day was significantly better than for those given $0-99 \mathrm{mg} /$ day (log-rank: $\mathrm{p}=0.00004$; figure $1 \mathrm{~A}$ ), as was all-cause survival, $\mathrm{p}=0.00005$ (online supplementary figure S2). There were no significant differences in comorbidities between patients in $0-99 \mathrm{mg} /$ day and $\geq 100 \mathrm{mg}$ /day groups (online supplementary table S4). The survival curves of patients given no beta-blocker $(\mathrm{n}=74)$ were overlapping the curves of patients given $25-74 \mathrm{mg} /$ day $(\mathrm{n}=36 ; \mathrm{p}=0.67$; online supplementary figure S3) and these patients were combined in a $0-74 \mathrm{mg}$ /day group. Survival curves depicting three dose ranges: $0-74 \mathrm{mg} /$ day, $75-149 \mathrm{mg} /$ day and $\geq 150 \mathrm{mg} /$ day of metoprolol equivalents, the middle band encompassing the median dose, show the benefit of larger doses of beta-blocker most clearly. There was a significant log-rank for trend in reduced risk of disease-related deaths with increased dose $(p=0.00008$; figure 1B). The 10-year freedom from disease-related deaths for the three dose bands, 0-74, 75-149, $\geq 150$ $\mathrm{mg} /$ day, was $83.1 \%, 90.7 \%$ and $97.0 \%$, respectively. The 20 -year proportions were $65 \%, 74 \%$ and $86 \%$, respectively. The 10-year freedom from disease-related deaths of patients without beta-blocker therapy was $81.7 \%$. Analysis of total mortality confirmed a similar pattern (log-rank $\mathrm{p}_{\text {trend }}=0.00009$ ), with 10-year all-cause survival of $78.7 \%$, $88.8 \%$ and $91.1 \%$ in respective dose bands.

Verapamil therapy, on the other hand, was associated with increased risk on univariate analysis $(\mathrm{p}=0.014$; table 2).

\section{Predictors of disease-related death at latest follow-up}

On univariate Cox hazard analysis, female sex, age, NYHA class $\geq \mathrm{III}$, a gradient remaining $\geq 50 \mathrm{~mm} \mathrm{Hg}$ and a smaller left ventricle end-diastolic diameter were associated with a significantly increased risk. Progression to dilated end stage was observed in only $4 \%$. Larger beta-blocker dose was associated with lower risk of disease-related death also at latest follow-up $(\mathrm{p}=0.018)$. Verapamil/diltiazem was a risk factor on univariate, but not multivariate analysis. Neither use of amiodarone, disopyramide, ACE inhibitor nor spironolactone showed any significant influence on survival. Also at latest follow-up a higher beta-blocker dose remained an independent predictor associated with reduced risk of disease-related death in multivariate analysis $(p=0.021)$. Comorbidities were not independent predictors in the multivariate model (table 3 ).

For heart failure deaths specifically, female sex, verapamil/ diltiazem therapy, coexisting systemic hypertension and outflow gradient $\geq 50 \mathrm{~mm} \mathrm{Hg}$ remained independent risk predictors, whereas beta-blocker dose reduced risk $(\mathrm{p}=0.008)$ in the multivariate model (table 3; for univariate results see online supplementary table S5).

Multivariate analysis of risk factors, therapies and comorbidities in relation to total all-cause mortality is shown in online supplementary table S6. The risk predictors for total all-cause mortality were similar as for disease-related deaths: female sex, age, LVOT gradient $\geq 50 \mathrm{~mm} \mathrm{Hg}$ and maximal wall thickness. Higher daily dosage of betablockers was associated with better survival also on multivariate analysis for total mortality $(\mathrm{p}=0.008)$.

\section{Beta-blocker and postintervention gradient}

Patients not receiving early beta-blockers had significantly higher proportion of disease-related deaths, if post-treatment gradient was $\geq 30 \mathrm{~mm} \mathrm{Hg}$ (10-year proportion $39.1 \%$ ) than with gradients $<30 \mathrm{~mm} \mathrm{Hg}$ (10-year proportion $7.4 \%$; $\mathrm{p}=0.002$ ). Accordingly, we analysed whether the apparent protective effect of beta-blockers was present only in patients with a residual gradient of $\geq 30 \mathrm{~mm} \mathrm{Hg}$ after initial therapy. This appeared not to be the case as shown in figure $2 \mathrm{~A}, \mathrm{~B}$.

Some patients with good relief of outflow tract obstruction after interventional procedures had beta-blocker therapy reduced after intervention. We therefore explored whether postintervention beta-blocker dose influenced survival, and found that a beta-blocker dose 
Table 3 Predictor factors/protective factors for disease-related and heart failure death on Cox hazard regression as recorded at latest follow-up

\begin{tabular}{|c|c|c|c|c|c|}
\hline Variable & B & SE & $\operatorname{Exp}(B)$ & $95 \% \mathrm{Cl} \operatorname{Exp}(\mathrm{B})$ & $P$ value \\
\hline \multicolumn{6}{|c|}{ Univariate Cox hazard analysis for disease-related death } \\
\hline Female sex & 0.756 & 0.258 & 2.136 & 1.288 to 3.542 & 0.003 \\
\hline NYHA class $\geq I I I$ vs $\leq l l$ & 0.862 & 0.340 & 2.369 & 1.218 to 4.609 & 0.011 \\
\hline Body mass index & 0.000 & 0.002 & 1.000 & 0.995 to 1.005 & 0.989 \\
\hline Diabetes mellitus, Yes versus No & 0.108 & 0.363 & 1.114 & 0.547 to 2.271 & 0.766 \\
\hline Coronary artery disease, Yes versus No & 0.448 & 0.322 & 1.566 & 0.834 to 2.940 & 0.163 \\
\hline Atrial fibrillation, Yes versus No & 0.051 & 0.126 & 0.950 & 0.742 to 1.216 & 0.681 \\
\hline Chronic kidney disease & 0.074 & 0.479 & 1.077 & 0.422 to 2.752 & 0.877 \\
\hline Chronic obstructive pulmonary disease & 0.403 & 0.402 & 1.496 & 0.681 to 3.289 & 0.316 \\
\hline $\operatorname{LVEDD~(mm)~}$ & -0.047 & 0.023 & 0.954 & 0.912 to 0.998 & 0.040 \\
\hline Ejection fraction (\%) & -0.049 & 0.996 & 0.952 & 0.135 to 6.706 & 0.961 \\
\hline Left atrium diameter (mm) & -0.004 & 0.020 & 0.995 & 0.996 to 1.035 & 0.824 \\
\hline LVOT gradient (mm Hg) & 0.013 & 0.003 & 1.013 & 1.007 to 1.018 & $<0.001$ \\
\hline LVOT gradient at rest $\geq 30$ vs $<30(\mathrm{~mm} \mathrm{Hg})$ & 0.016 & 0.006 & 1.016 & 1.004 to 1.028 & 0.008 \\
\hline LVOT gradient at rest $\geq 50 \mathrm{vs}<50(\mathrm{~mm} \mathrm{Hg})$ & 1.526 & 0.270 & 4.600 & 2.710 to 7.810 & $<0.001$ \\
\hline Myectomy & 0.086 & 0.148 & 1.090 & 0.815 to 1.458 & 0.562 \\
\hline Pacemaker therapy & 0.073 & 0.253 & 1.076 & 0.655 to 1.766 & 0.773 \\
\hline ACE inhibitor use, Yes versus No & -0.057 & 0.279 & 0.945 & 0.547 to 1.631 & 0.838 \\
\hline Spironolactone use, Yes versus No & -0.029 & 0.157 & 0.972 & 0.714 to 1.322 & 0.855 \\
\hline Statin treatment, Yes versus No & -0.759 & 0.401 & 0.468 & 0.213 to 1.028 & 0.059 \\
\hline Implantable cardioverter-defibrillator (ICD) & -1.196 & 0.598 & 3.305 & 1.023 to 10.678 & 0.046 \\
\hline \multicolumn{6}{|c|}{ Multivariate Cox hazard analysis, disease-related death (96.8\% complete data, 3.2\% missing) } \\
\hline Female sex & 1.197 & 0.389 & 3.310 & 1.543 to 7.100 & 0.002 \\
\hline Age & 0.024 & 0.011 & 1.025 & 1.003 to 1.047 & 0.025 \\
\hline LVOT gradient at rest $\geq 50$ vs $<50$ (mm Hg) & 1.262 & 0.374 & 3.533 & 1.697 to 7.355 & 0.001 \\
\hline NYHA class $\geq 1 I I$ vs $\leq I I$ & 0.846 & 0.383 & 2.330 & 1.100 to 4.934 & 0.027 \\
\hline Beta-blocker dose (mg/day) & -0.005 & 0.002 & 0.995 & 0.991 to 0.999 & 0.021 \\
\hline \multicolumn{6}{|c|}{ Multivariate Cox hazard analysis, heart failure death (96.8\% complete data, 3.2\% missing) } \\
\hline Female sex & 1.036 & 0.352 & 2.819 & 1.414 to 5.620 & 0.003 \\
\hline LVOT gradient at rest $\geq 50 \mathrm{vs}<50(\mathrm{~mm} \mathrm{Hg})$ & 0.014 & 0.007 & 1.014 & 1.001 to 1.028 & 0.032 \\
\hline Systemic hypertension, Yes versus No & 0.726 & 0.336 & 2.066 & 1.069 to 3.995 & 0.031 \\
\hline Verapamil/diltiazem use, Yes versus No & 1.036 & 0.414 & 2.817 & 1.251 to 6.343 & 0.012 \\
\hline Beta-blocker dose (mg/day) & -0.005 & 0.002 & 0.995 & 0.991 to 0.999 & 0.008 \\
\hline
\end{tabular}

Significant negative values of $B$ suggest reduction in risk. Bold text high-light statistically significant findings.

ACE, angiotensin converting enzyme; LVEDD, left ventricle end-diastolic diameter; LVOT, left ventricular outflow tract;NYHA, New York Heart Association. 


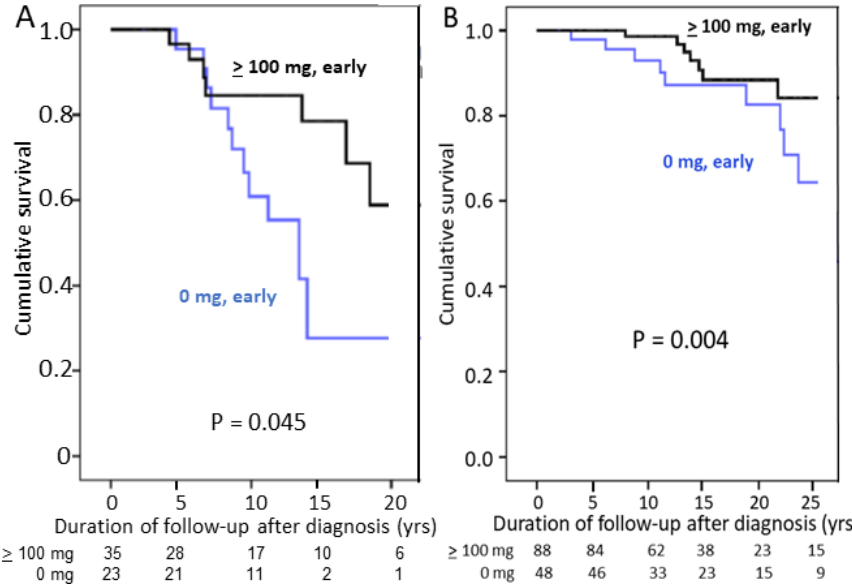

Figure 2 (A) Kaplan-Meier survival curve comparing freedom from disease-related death in patients with residual gradient on treatment $\geq 30 \mathrm{~mm} \mathrm{Hg}$ in patients with a median initial dose of $\geq 100 \mathrm{mg} /$ day of metoprolol equivalents (black curve) to patients not receiving any beta-blocker (blue curve). There are few patients with gradients $\geq 30 \mathrm{~mm} \mathrm{Hg}$, but the difference is nevertheless significant $(p=0.045)$. (B) KaplanMeier survival curve comparing freedom from disease-related death in patients with residual gradient on treatment $<30$ $\mathrm{mm} \mathrm{Hg}$ in patients with a median initial dose of $\geq 100 \mathrm{mg} /$ day of metoprolol equivalents (black curve) which also have significantly better survival $(p=0.004)$ to patients not receiving any beta-blocker (blue curve). The numbers below the curves indicate the number of patients remaining in the survival curves.

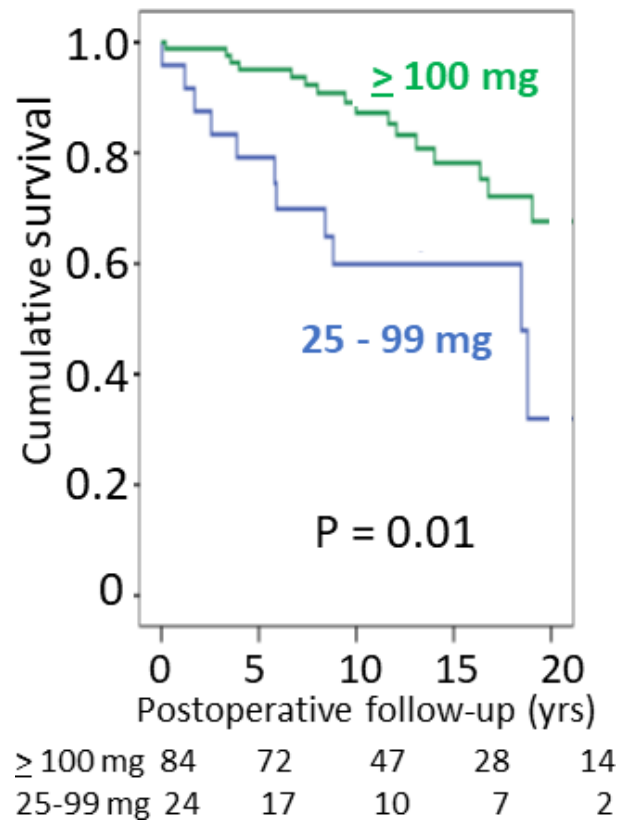

Figure 3 Kaplan-Meier survival curves illustrating postintervention freedom from disease-related death in patients who have received interventional treatment with either short atrioventricular (AV) delay pacing or myectomy related to postintervention dose of beta-blocker therapy. The green curve illustrates survival with postintervention dose of $\geq 100 \mathrm{mg} /$ day of metoprolol equivalents, and the blue curve the inferior survival with metoprolol-equivalent doses of $25-99 \mathrm{mg} /$ day $(p=0.010)$. $\geq 100 \mathrm{mg}$ metoprolol equivalent/day was associated with significantly better outcome than low dose (25-99 mg) (figure 3).

\section{Effect of comorbidities}

There was no significant skewing of proportion of patients with comorbidity between patient groups in figure 3 (online supplementary table S7). Furthermore, there was no excess comorbidity in patients who had died a disease-related death (online supplementary table S8).

\section{DISCUSSION}

\section{Risk factors for long-term mortality}

Age, female sex and an unrelieved LVOT gradient were significant risk factors for disease-related mortality in this study of a geographical cohort of patients with HOCM. These have previously been reported by others. ${ }^{1-10}$ It is noteworthy that in our geographical cohort of patients with HOCM, SCD caused a small proportion of disease-related deaths, in spite of a low rate of ICD implantations $(6.4 \%)$, in contrast to reports from tertiary centres. For example, in a multicentre study of patients with similar age profile as ours, SCD comprised $39 \%$ of deaths in the HOCM group, with annual SCD mortality of $0.75 \%-$ $1.26 \%$ in various groups ${ }^{11}$ compared with an annual SCD mortality of $0.37 \%$ in our study. This may explain why risk factors thought to be important for SCD, such as family history of SCD and maximal wall thickness $\geq 3 \mathrm{~cm}$, failed to show significant impact on total disease-related mortality in our cohort, in contrast to an LVOT gradient $\geq 50 \mathrm{~mm} \mathrm{Hg}$. A recent study identified unmet clinical needs in population-based patients with HCM including a 4.3 times excess of heart failure, and that heart failure was more common than SCD and ventricular arrhythmias combined, ${ }^{12}$ as in our study. This underlines the importance of evaluating therapies that may reduce non-sudden and heart failure-related mortality in HOCM, like a good control of significant risk factors for heart failure death on multivariate analysis in this study such as systemic hypertension and LVOTO.

\section{Effect of therapy on risk of death}

Surgical septal myectomy has long been considered the gold standard treatment for therapy-resistant patients with $\mathrm{HOCM},{ }^{213} 14$ and suggested to give superior survival compared with conservative treatment. ${ }^{15}$ However, the conservatively treated group was on average 10 years older, and a reduction in cardiovascular mortality in the intervention group could not be substantiated. ${ }^{15}$ We have earlier reported that in a geographical cohort of patients with HOCM, neither myectomy nor pacing was significantly associated with improved survival compared with conservative medical therapy, although both treatments improved NYHA class. ${ }^{5}$ In the present study, neither univariate nor multivariate Cox hazard analysis could detect that myectomy or pacing was associated with a survival benefit that was independent of other risk factors such as age (tables 2 and 3). Thus, the only therapy 
associated with significant improvement of survival on multivariate analysis in our cohort was beta-blocker therapy. The observed excess mortality in heart failure in patients with HOCM receiving verapamil/diltiazem is concerning but should be interpreted with caution due to the small numbers receiving calcium-blockers. This merits further study in HCM populations with higher use of calcium channel blockers than ours.

\section{Benefit of beta-blocker therapy}

Beta-blocker therapy reduces LVOT gradient in HOCM, both at rest and during exercise, and improves symptoms, diastolic function and exercise capacity. ${ }^{16-21}$ In childhood $\mathrm{HCM}$, it is also associated with improved survival ${ }^{22}$ in a dose-related manner, ${ }^{23} 24$ and reduces risk of SCD. ${ }^{25}$ It has been claimed that beta-blocker therapy does not affect survival in adult $\mathrm{HCM},{ }^{26}$ although Frank et $a l^{27}$ reported particularly low SCD mortality $(0.3 \%)$ in patients treated with relatively high doses of propranolol, aiming for $\geq 320$ $\mathrm{mg}$ /day. In another study on 163 consecutive patients, average follow-up of 5.3 years, of whom $40 \%$ received beta-blockers, beta-blocker was significantly associated with improved outcome, HR 0.25 (95\% CI 0.08 to 0.77 ), $\mathrm{p}=0.0120 .^{9}$ In a larger recent study that focused on sex differences in survival (3673 patients), beta-blocker therapy (dose unspecified) was associated with a lower all-cause mortality (they were unable to separate cardiac mortality). ${ }^{28}$ These observations support our finding that beta-blocker therapy emerges as a significantly protective factor for disease-related deaths even on multivariate analysis (tables 2 and 3, and figure 1A,B), confirmed in an all-cause mortality analysis. Previous studies have included both non-obstructive and obstructive HCM, and the effect we observed might be due to gradient reduction or to the doses employed. Findings illustrated in figure 2B make the former mechanism unlikely. Among patients receiving beta-blockers the early median metoprolol dose for survivors was $162.5 \mathrm{mg}$ metoprolol/day, and median latest follow-up dose was $175 \mathrm{mg}$ /day. Thus, the survivor doses are within the range of doses used in the prospective randomised trials on heart failure that have demonstrated metoprolol significantly reduces cardiac mortality. ${ }^{29}$ A dose effect would tally with studies that show heart rate lowering efficacy of beta-blocker dose correlates to reduction in mortality in patients with heart failure. $^{30}$

However, our significant results are quite likely also a question of statistical power. Melacini et al's negative study from $2007^{26}$ lacked statistical power to detect a protective effect of beta-blockers: out of 293 patients only 26\% were treated with beta-blockers, giving at most 456 patient-years, whereas our study has 2613 patient-years on beta-blocker therapy. With our study there are now three studies from patient cohorts of very different ethnic origin that report statistically significant protection from beta-blocker use. The HR for patients with beta-blocker use from diagnosis was 0.49 (95\% CI 0.30 to 0.81$)$ in our cohort. Furthermore, the association was dose dependent (figure 1A,B), suggesting a pharmacological effect and not a chance association.

\section{Therapy with mild or latent obstruction}

The finding of an apparent survival benefit of continued adequate beta-blocker therapy even in patients where interventions have reduced gradients to below $30 \mathrm{~mm}$ $\mathrm{Hg}$ might indicate that this therapy could be protective also in the absence of LVOT obstruction. A prospective randomised trial in non-obstructive HCM has not been performed. The observation that it takes around 5 years for survival curves to diverge significantly (figure 1A) indicates that the effect may be particularly on myocardial preservation perhaps affecting progress of fibrosis, rather than reducing SCD mortality as reported with higher paediatric dosages. ${ }^{25}$ Lacking controlled trials, it would be desirable that large international registries for HCM should collect and publish data on mortality related to pharmacotherapy, both type and dose.

\section{Incomplete relief of LVOTO}

Our results confirm earlier studies that patients in whom therapeutic interventions have failed to reduce the resting gradient below $30 \mathrm{~mm} \mathrm{Hg}$ have a worse prognosis ${ }^{13}$; the risk is incremental and the prognosis is particularly poor with gradients $\geq 50 \mathrm{~mm} \mathrm{Hg}$. This underlines the importance of intensifying treatment even in asymptomatic patients if a sizeable resting gradient remains.

\section{Strengths and limitations}

The strengths of this study are the long follow-up and $100 \%$ complete cause of death information. Retrospective studies on complete unselected geographical cohorts are the method of choice in identifying risk factors for adverse outcomes, but it is not the method of choice for evaluating the effects of drug therapy, where prospective randomised trials would be preferable. The fact that there is no published prospective randomised drug trial using mortality as endpoint in patients with HCM, not even from supraspecialised centres, testifies to the difficulties in organising such studies. Particular handicap is studying drugs such as beta-blockers that are out of patent so that pharmaceutical companies have no incentive for financial support.

\section{CONCLUSIONS}

In this unselected geographical cohort we found that heart failure was a dominant cause of death in HOCM, and showed that female sex, age and persisting LVOT obstruction were important independent risk factors for disease-related, and specifically heart failure-related deaths. The data indicate that beta-blocker therapy would be beneficial even in asymptomatic LVOT obstruction, aiming for doses of at least $150 \mathrm{mg}$ / day metoprolol equivalents. We hope these results will stimulate international collaborative prospective randomised studies of adequate duration of the effect of pharmacotherapy on survival in HCM. 
Author affiliations

${ }^{1}$ Department of Molecular and Clinical Cardiology, Institute of Medicine, Sahlgrenska Akademy at the University of Gothenburg and Sahlgrenska University Hospital, Gothenburg, Sweden

${ }^{2}$ Cardiac Department, Uddevalla Hospital, Uddevalla, Sweden

${ }^{3}$ Pediatrics, Institute of Clinical Sciences, Sahlgrenska Academy at University of Gothenburg and Sahlgrenska University Hospital, Gothenburg, Sweden

Acknowledgements We are most grateful for the helpful assistance of medical and clerical staff at the Sahlgrenska, Östra, Mölndal, Uddevalla, Trollhättan, Skövde, Lidköping, Alingsås, Borås and Kungälv Hospitals in the West Götaland Region, Sweden.

Contributors The design of the study was agreed between DJ, IÖ-S, BA and MS. DJ, N-JA and IÖ-S have collected the patient information. The statistical analyses have been carried out by DJ and IÖ-S. All authors have contributed to the writing and the revisions of the manuscript. The authors are not reusing any figures or tables previously published.

Funding The study was supported by grants from the Swedish Heart and Lung Foundation (Hjärt-Lungfonden; 20080510), and by a Swedish state ALF agreement (Gothenburg University) project grant (ALFgbg-544981).

Competing interests None declared.

Patient consent for publication Not required.

Ethics approval The study complies with the Helsinki convention and was approved by the University of Gothenburg Ethics Committee (approval number ÖS1012-12).

Provenance and peer review Not commissioned; externally peer reviewed.

Data availability statement Data are available upon reasonable request. All data relevant to the study are included in the article or uploaded as supplementary information.

Open access This is an open access article distributed in accordance with the Creative Commons Attribution Non Commercial (CC BY-NC 4.0) license, which permits others to distribute, remix, adapt, build upon this work non-commercially, and license their derivative works on different terms, provided the original work is properly cited, appropriate credit is given, any changes made indicated, and the use is non-commercial. See: http://creativecommons.org/licenses/by-nc/4.0/.

\section{REFERENCES}

1. Maron MS, Olivotto I, Betocchi S, et al. Effect of left ventricular outflow tract obstruction on clinical outcome in hypertrophic cardiomyopathy. N Engl J Med Overseas Ed 2003;348:295-303.

2. Gersh BJ, Maron BJ, Bonow RO, et al. 2011 ACCF/AHA guideline for the diagnosis and treatment of hypertrophic cardiomyopathy: a report of the American College of cardiology Foundation/American Heart Association Task Force on practice guidelines. J Am Coll Cardiol 2011;58:e212-60.

3. Elliott PM, Anastasakis A, Borger MA, et al. 2014 ESC guidelines on diagnosis and management of hypertrophic cardiomyopathy: the task Force for the diagnosis and management of hypertrophic cardiomyopathy of the European Society of cardiology (ESC). Eur Heart J 2014;35:2733-79.

4. Maron BJ, Epstein SE. Hypertrophic cardiomyopathy: a discussion of Nomenclature. Am J Cardiol 1979;43:1242-4.

5. Javidgonbadi D, Abdon N-J, Andersson B, et al. Short atrioventricular delay pacing therapy in young and old patients with hypertrophic obstructive cardiomyopathy: good long-term results and a low need for reinterventions. Europace 2018;20:1683-91.

6. van Herwaarden CL, Binkhorst RA, Fennis JF, et al. Effects of propranolol and metoprolol on haemodynamic and respiratory indices and on perceived exertion during exercise in hypertensive patients. Heart 1979;41:99-105.

7. Woo A, Williams WG, Choi R, et al. Clinical and echocardiographic determinants of long-term survival after surgical myectomy in obstructive hypertrophic cardiomyopathy. Circulation 2005;111:2033-41.
8. Olivotto I, Maron MS, Adabag AS, et al. Gender-related differences in the clinical presentation and outcome of hypertrophic cardiomyopathy. J Am Coll Cardiol 2005;46:480-7.

9. Lee C-H, Liu P-Y, Lin L-J, et al. Clinical characteristics and outcomes of hypertrophic cardiomyopathy in Taiwan--a tertiary center experience. Clin Cardiol 2007;30:177-82.

10. Wang Y, Wang J, Zou Y, et al. Female sex is associated with worse prognosis in patients with hypertrophic cardiomyopathy in China. PLoS One 2014:9:e102969.

11. Vriesendorp PA, Liebregts M, Steggerda RC, et al. Long-term outcomes after medical and invasive treatment in patients with hypertrophic cardiomyopathy. JACC Heart Fail 2014;2:630-6.

12. Pujades-Rodriguez M, Guttmann OP, Gonzalez-Izquierdo A, et al. Identifying unmet clinical need in hypertrophic cardiomyopathy using national electronic health records. PLoS One 2018;13:e0191214.

13. Schönbeck MH, Brunner-La Rocca HP, Vogt PR, et al. Long-term follow-up in hypertrophic obstructive cardiomyopathy after septal myectomy. Ann Thorac Surg 1998;65:1207-14.

14. Ommen SR, Maron BJ, Olivotto I, et al. Long-term effects of surgical septal myectomy on survival in patients with obstructive hypertrophic cardiomyopathy. J Am Coll Cardiol 2005;46:470-6.

15. Ball W, Ivanov J, Rakowski H, et al. Long-term survival in patients with resting obstructive hypertrophic cardiomyopathy comparison of conservative versus invasive treatment. J Am Coll Cardiol 2011;58:2313-21.

16. Cherian G, Brockington IF, Shah PM, et al. Beta-adrenergic blockade in hypertrophic obstructive cardiomyopathy. Br Med J 1966;1:895-8.

17. Frank MJ, Abdulla AM, Canedo MI, et al. Long-term medical management of hypertrophic obstructive cardiomyopathy. Am J Cardiol 1978;42:993-1001.

18. Frank MJ, Abdulla AM, Watkins LO, et al. Long-term medical management of hypertrophic cardiomyopathy: usefulness of propranolol. Eur Heart J 1983;4 Suppl F:155-64.

19. Alvares RF, Goodwin JF. Non-invasive assessment of diastolic function in hypertrophic cardiomyopathy on and off beta adrenergic blocking drugs. Heart 1982;48:204-12.

20. Bourmayan C, Razavi A, Fournier C, et al. Effect of propranolol on left ventricular relaxation in hypertrophic cardiomyopathy: an echographic study. Am Heart J 1985;109:1311-6.

21. Maron BJ, Spirito P, Green KJ, et al. Noninvasive assessment of left ventricular diastolic function by pulsed Doppler echocardiography in patients with hypertrophic cardiomyopathy. J Am Coll Cardiol 1987;10:733-42.

22. Östman-Smith I, Wettrell G, Riesenfeld T. A cohort study of childhood hypertrophic cardiomyopathy: improved survival following high-dose beta-adrenoceptor antagonist treatment. J Am Coll Cardiol 1999;34:1813-22.

23. Östman-Smith I, Wettrell G, Keeton B, et al. Echocardiographic and electrocardiographic identification of those children with hypertrophic cardiomyopathy who should be considered at high-risk of dying suddenly. Cardiol Young 2005;15:632-42.

24. Östman-Smith I. Hypertrophic cardiomyopathy in childhood and adolescence - strategies to prevent sudden death. Fundam Clin Pharmacol 2010;24:637-52.

25. Östman-Smith I, Sjöberg G, Rydberg A, et al. Predictors of risk for sudden death in childhood hypertrophic cardiomyopathy: the importance of the ECG risk score. Open Heart 2017;4:e000658.

26. Melacini P, Maron BJ, Bobbo F, et al. Evidence that pharmacological strategies lack efficacy for the prevention of sudden death in hypertrophic cardiomyopathy. Heart 2007;93:708-10.

27. Frank MJ, Stefadouros MA, Watkins LO, et al. Rhythm disturbances in hypertrophic cardiomyopathies: relationship to symptoms and the effect of 'complete' beta blockade. Eur Heart J 1983;4 Suppl $\mathrm{F}: 235-43$

28. Geske JB, Ong KC, Siontis KC, et al. Women with hypertrophic cardiomyopathy have worse survival. Eur Heart J 2017;38:3434-40.

29. Wikstrand J, Hjalmarson A, Waagstein F, et al. Dose of metoprolol $\mathrm{CR} / \mathrm{XL}$ and clinical outcomes in patients with heart failure: analysis of the experience in metoprolol $\mathrm{CR} / \mathrm{XL}$ randomized intervention trial in chronic heart failure (MERIT-HF). J Am Coll Cardiol 2002;40:491-8

30. Kotecha D, Flather MD, Altman DG, et al. Heart Rate and Rhythm and the Benefit of Beta-Blockers in Patients With Heart Failure. J Am Coll Cardiol 2017;69:2885-96. 